\title{
Situations, Difficulties and Solutions: Reflection on Ideological and Political Construction of Sino-foreign Cooperative Program Courses in Colleges
}

\author{
Qiao Meng ${ }^{1, *}$ Haiying Long ${ }^{2}$ \\ ${ }^{1}$ GuangZhou College of Commerce, Guangzhou, China; St. Paul University Philippines, Tuguegarao City, Philippines \\ ${ }^{2}$ GuangZhou College of Commerce, Guangzhou, China; St. Paul University Philippines, Tuguegarao City, Philippines \\ ${ }^{*}$ Corresponding author. Email: 86779513@qq.com
}

\begin{abstract}
Because of the participation of foreign teachers, foreign teaching materials, foreign teaching models and other foreign educational elements in Sino-foreign cooperative program education, the promotion of curriculum ideological and political education in the course faces the dilemma of “conflict” between Chinese and Foreign Teachers' teaching ideas, "incompatibility" between Chinese and foreign teaching materials, and "disconnection" between Chinese and foreign campuses. We should take problems as the guide, stick to the goal of fostering character and civic virtue, combine the centripetal force of the curriculum thought and politics, improve its traction, and strengthen its continuity. Through resolving the key and difficult problems in the process, we can expand the range and depth of the education system of Sino-foreign cooperative projects, and actively construct a new mode of ideological and political education with distinctive features under the diversified background of Sino-foreign cooperative program.
\end{abstract}

Keywords: Sino-foreign cooperative program, Curriculum ideology and politics, Conflict, Solution.

\section{现状、困境与出路：高校中外合作办学项目课程思政} 建设审思

蒙巧 ${ }^{1, *}$, 龙海英 ${ }^{2}$

1 广州商学院，广州，中国; 菲律宾圣保罗大学, 土格加劳市, 菲律宾

2 广州商学院, 广州, 中国; 菲律宾圣保罗大学, 土格加劳市, 菲律宾

“通讯作者. 由箱: 86779513@qq. com

\section{中文摘要}

高校中外合作办学项目由于其办学过程中有国外师资、国外教材、国外教学模式等国外教育元素的参与, 课程 思政的推进面临中外教师教学理念 “有冲突” , 中外教材内容要素 “难融合” , 中外校园推进实施 “不衔接” 的困境。以问题为导向, 坚持立德树人为目标, 集合课程思政的向心力, 提升课程思政的牵引力, 加强课程思 政的接续力, 突破课程思政建设过程中存在的重点难点问题, 能科学合理拓展中外合作办学项目专业体系设置 的广度和深度，积极构建中外合作办学多元化背景下具有鲜明特色的思想政治教育工作新模式。

关键词: 中外合作办学; 课程思政; 困境; 出路. 


\section{1. 引言}

中外合作办学作为我国教育对外开放的重要载体, 近十多年来蓬勃发展, 满足了学生不出国门享受高质 量国际化教育的需求。中外合作办学通过引进国外高 校优质教育资源, 结合国内已有的高校资源, 共同合 作举办的以中国公民为主要招生对象的人才培养模 式, 致力于培养中国社会主义建设事业的各类人才, 符合中国教育事业发展的需要, 是我国高等教育事业 的重要组成部分, 但由于过程中有国外高校教育元素 的参与, 包括国外师资、国外教材、国外教学培养模 式等元素, 在中外合作办学多元文化中如何坚持不解 用习近平新时代中国特色社会主义思想铸魂育人、如 何培育和践行社会主义核心价值观、如何教育引导学 生传承中华文脉，面临着特殊的机遇与挑战。

\section{2. 高校中外合作办学项目课程思政建设的研 究现状}

历数古今中外, 各国都高度重视思想政治教育, 通过查阅文献资料及搜索各平台数据库资源, 笔者发 现, 国外执政党的思想政治教育更多地涉及道德、审 美、权力与义务等, 并与教育学、心理学、伦理学等 学科结合起来, 而“课程思政”这一概念在国外并无专 门的理论阐释。国内, 党的十八大以来, 党中央、国 务院高度重视高校人才培养和思想政治工作, 并出台 了一系列的决策部署, 进一步凸显了高校作为思想政 治教育主阵地的地位, 同时也对高校思想政治工作提 出了新目标与新要求。各高校结合自身的办学特色, 因地制宜、因校制宜, 围绕思想政治教育工作的建设 目标、工作思路、建设内容、工作落实、建设效果等 进行了深入研究，相关的研究、实践与建设成果也日 益丰富，“目前已初步形成高校普遍重视、院系广泛 动员、教师积极参与的局面”[1]。而作为我国教育对外 开放重要载体的中外合作办学项目, 由于过程中有国 外高校教育元素的参与, 课程思政的推进更具有特殊 性和复杂性, 目前相关研究著述逐年增多, 但仍有很 大的挖掘空间, 已有的相关研究呈现出以下三个特点:

\section{1. 研究发展逐步呈现“体系性”}

课程思政是一项系统工程, 指在各类课程中有机 融入思想政治教育元素, 与思想政治理论课形成协同 效应, 实现专业课程与思政课程同向同行的教育教学 理念、方法与实践体系。因此, 课程思政建设要坚持 体系思维和一体设计。在制度体系设计层面, 目前一 些高校及相关研究者已逐步探索高校中外合作项目 在课程体系、人才培养目标、办学质量评估指标、学 业评价体系等方面的系统性构建。早在21世纪初, 邱 妘就宁波大学中加合作办学项目的实践与探索, 对该 项目国际化课程体系进行初步的研究探讨 ${ }^{[2]}$; 庄智象、 韩天霖等在界定国际化创新型外语人才的内涵及其 培养方式的基础上,探讨国际化创新型人才培养的教 材体系构建 ${ }^{[3]}$; 殷辉、李晓雪等从定位适应度、资源
引进度、教学保障度、实践贡献度、社会满意度五 个方面初步确定了 24 个评估指标，运用因子分析提炼 出14个有效指标和确定了相应的权重, 构建中外合作 办学质量指标体系 ${ }^{[4]}$; 李昕、陈宇等分析了中外合作 办学项目思政课程面临的诸多挑战,探索构建全员参 与、全过程评价、实践考核加日常行为表现评价的中 外合作办学思政课程学业评价体系 ${ }^{[5]}$; 曾佳从价值、 内容与实践三个维度的科学设计, 加强中外合作办学 项目的课程体系构建 ${ }^{[6]}$ 。

\section{2. 研究指向逐步趋于 “个体化”}

教育教学过程中始终要坚持教师的主导性和学生 的主体性相统一，课程思政的实施离不开教师的主导 作用, 也要兼顾学生个体的认知规律和接受特点, 充 分发挥学生的主体性作用。一方面, 课程思政聚焦学 生个体认知发展。学生是教育教学活动的主体, 是知 识的发现者与探索者, 学生的学习成长本身就是个体 身心发展的社会化过程, 在教育教学活动中呈现出能 动性、创新性、独特性、整体性等多种品质特征。课 程思政聚焦学生个体发展与主体地位, 即是唤醒学生 的主体意识、智力潜能与个性发展并培养学生形成正 确的价值取向。于学生个体思想政治教育层面, 目前 一些高校及相关研究者已对中外合作办学高校如何 加强学生的思想政治教育工作，主要聚焦中外合作办 学背景下学生的党建工作、思政课程建设、辅导员工 作思路等进行探索。例如, 时昌桂、冯跃飞等认为中 外合作办学 “双校园”模式下由于课程压力过大等原 因, 学生的政治意思淡薄, 导致思政教育不明显 ${ }^{[7][8]}$ 。 另一方面, 课程思政关注教师个体能力支撑。教师是 整个教育活动的组织者和引领者, 需要明确教学目标, 整合教学材料, 选择教学方法, 传授教学知识, 引导 价值取向, 在教育教学活动中起着主导作用。教师作 为课程思政建设的主体, 是课堂教学的第一管理人, 是推进课程思政建设的 “主力军”。因此, 教师个体的 知识结构、政治素养、价值理念、个人鬼力等的高低 将直接关系到课程思政的效果。目前一些高校及相关 研究者已着手中外合作办学背景下高校思想政治教 育的师资队伍建设问题研究。例如，魏新强通过问卷 调查研究, 指出中外合作办学师资队伍在稳定性、教 学素养、科研能力等方面有待加强 ${ }^{[9]}$; 孙珂系统探讨 中外合作办学项目教师的学历、职称、年龄结构等方 面存在的问题与对策 ${ }^{[10]}$; 卿志军认为在中外合作办学 中存在中方教师专业强语言弱、外方教师管理不到位 等普遍性问题亟待解决 ${ }^{[11]}$ 。

\section{3. 研究范围逐步涵盖 “多维度”}

扎实推进课程思政建设，着力构建全员全过程全 方位课程思政育人体系, 需要全方位、多维度把握各 类学科、专业、课程的特点与规律, 牢固树立知识传 授与价值引领同向同行的教学理念，找准思政元素与 各类专业、各类学科、各类课程、各类教学手段等在 教学实践中有机融合的不同切入点，才能做到因地制 
宜、有的放矢、精准施策, 达到春风化雨、润物无声 的效果。因此, 在课程思政教育教学改革与实践路径 方面, 如何把思想政治教育元素具体化到中外合作办 学高校或项目的某个专业、某类课程、某种教学手段 模式中进行探索、实践与验证, 成了高校和研究者近 期关注的焦点。如李进芳聚焦师范院校中外合作办学 项目经管类专业的学科特点和生源特征推进课程思 政 ${ }^{[12]}$; 陈薇、侯滟斯结合工科性中外合作办学学院的 特点与优势,探索与实践教育紧密结合的思政教育新 模式, 培养具有社会责任感、工匠精神、创新精神等 的高素质复合型国际工程人才[13]。徐晔、许淑瑶等认 为英语教学在中外合作办学项目其中起着至关重要 的作用, 探讨通过优化英语课程教学与设计, 实现语 言的提升和价值的引领 ${ }^{[14]}[15]$ 。

\section{3. 高校中外合作办学项目课程思政建设的困 境}

如上所述, 随着课程思政理念的提出与推进, 大 部分中外合作办学高校在传统思想政治理论课程的 基础上, 积极以“课程思政”作为切入点推动思想政治 教育改革, 深入挖掘其他各类课程的价值引领与育人 功能, 近两年的实践及理论研究成果剧增。但笔者也 发现, 作为我国教育对外开放重要载体的中外合作办 学项目, 由于过程中有国外高校教育元素的参与, 包 括国外师资、国外教材、国外教学培养模式等, 课程 思政的推进更具有特殊性、复杂性与紧迫性, 面临着 诸多挑战与困境。在综合前人研究的基础上, 依据本 人所在高校的中外合作办学项目多年实践经验, 本文 聚焦中外合作办学背景下高校课程思政教学实践, 以 广州商学院最具品牌特色、社会评价高、办学效果突 出的广州商学院-美国贝佛大学 (Bellevue University) 物流管理双学位项目（以下简称“广商-BU”双学位项 目）为例, 揭示中外合作办学项目由于师资配置、教 材建设、课程教学模式等特殊性而在课程思政推进过 程中面临的亟待解决的问题。

\section{1. 文化背景“有差异”，外籍教师与中方教师 课程思政教学理念“有冲突”}

外籍教师与中方教师协同授课是高校中外合作办 学项目培养国际化人才的一大亮点。然而高校在推进 课程思政教学改革中, 部分中国教师因缺乏教学改革 的“动力”、“意愿”和“能力”，或对教学改革预期效果 缺乏“自信”，因而面临着“不愿”“不会”“不敢”和“不需” 的困境 ${ }^{[17]}$, 外籍教师更是如此。由于中西文化的差异 与思维模式的不同, 外籍教师对中国文化缺乏全面的 认识, 对课程思政不太理解或对课程思政存在主观上 的偏颇而不愿参与; 外籍教师的质量也良莠不齐, 对 课程思政的理解不透或由于自身水平能力不够而不 敢参与; 也有部分外籍教师满足于现有的语言或知识 教学, 认为课程思政是中方老师的职责因而不需参与。 因此, 在中外合作办学项目课程思政推进过程中, 如
何有效发挥中国教师的积极性、主动性与创造性，如 何激励外籍教师的认同性与参与性，实现“三全育人” 的新局面, 具有必要性与紧迫性, 是该类项目亟待解 决的重要问题。

究其原因，高校中外合作办学项目必须包括中方 教师和一定数量比例的外籍教师。2006年教育部文件 中明确指出要加强中外合作办学的质量管理, 特别是 “双校园”办学模式的中外合作办学项目, 对其办学过 程中引进优质教育资源的数量提出了具体要求, 在师 资引进方面, 外国教育机构教师担负的专业核心课程 的门数和教学时数应当占中外合作办学项目全部课 程和全部教学时数的三分之一以上 ${ }^{[16]}$ 。以笔者所在的 “广商-BU”双学位项目语言公共必修课为例, 该项目 在中国广州商学院校区的语言课程教师总计 20 名, 其 中中国籍英语教师 15 名，占比 $75 \%$, 外国籍英语教师 5 名（包括澳大利亚籍 2 名、意大利籍 1 名、奥地利籍 1 名、瑞士籍1名），占比 $25 \%$ 。同时，英语语言课程 分为英语听力、英语阅读、英语写作与英语会话四大 模块, 中国籍英语教师主要担任英语听力、英语阅读 等输入性较强的课程教学, 而外国籍英语教师主要负 责英语会话、英语写作等输出性为主的课程教学。以 上缘由, 外籍教师在课程教学中占据相当的比列且直 接参与课堂教学, 课程思政的推进变得更加紧迫和重 要。

\section{2. 中外教材“难取舍”，海外教材与国内教材 课程思政内容要素“难融合”}

早在1985年，中央教育部明确指出：“教材建设是 高等学校的一项基本建设。各校要与抓师资、设备工 作一样抓好教材建设工作” [18]。国外教材与国内教材 协同育人是高校中外合作办学项目培养国际化人才 的一大特色。中外合作办学项目教材一般包括国外原 版教材、国内出版教材和教师自编校本教材。中外合 作办学项目要实现办学项目课程内容国际化, 培养具 有家国情怀和全球视野的应用型人才，除了使用好本 土的国内教材, 还需适量引进国外原版教材, 开发符 合自身实际的校本教材, 实现优势互补, 无疑具有重 要意义。然而, 由于原版教材由国外学者编写及国外 出版社出版, 其教学内容与质量的把关, 涉及的人文 环境、社会背景、价值理念、思维方式等的不同，对 于中外合作办学项目整理课程思政的育人设计与开 展, 提出了更高的挑战。

以“广商-BU”双学位项目语言公共必修课为例, 笔者梳理该项目的近三年的语言课程教材征订记录, 英语听、说、读、写课程的教材主要包括海外原版 教材Academic skills系列 (牛津大学出版社出版), Inside Reading系列 (牛津大学出版社出版), Oxford Word Skills系列 (牛津大学出版社出版) 、 (Open forum 系列 (牛津大学出版社出版) 、Longman Academic Writing Series（培生教育出集团出版），国 内教材则主要包括Listen to this系列 (外语教学与研究 
出版社），《剑桥实境英语》系列（西安交通大学出 版社）、《新一代大学英语综合教程》系列（外语教 学与研究出版社) 等, 海外原版教材的使用比例甚至 高过国内教材的使用。

一方面，国内教材大多由国内具有多年行业经验 的专家或教师编写, 能够较充分考量区域性的学生的 实际水平和需求, 让基础薄弱的学生能够在知识、能 力、技能等方面得到较系统的训练和提升。另一方面, 国外教材则由国外具有多年行业经验的专家或教师 编写, 能原汁原味体现编者的语言风貌、逻辑思维、 价值理念等, 是培养中外合作项目国际化人才的重要 工具。在新时代大思政的格局下, 如何以课程思政教 育教学改革为契机, 积极推动教材改革, 引进与构建 一批与中外合作办学目标相适应的有特色、高水平、 集知识传授、价值引领和能力培养为一体的系统性教 材任重道远且至关重要, 是中外合作办学项目当前亟 待解决的又一重要问题。

\section{3. 教学全程“不连费”，国外校园与国内高校 课程思政推进实施“不衔接”}

海外与国内 “双校园”协同模式是高校中外合作办 学项目培养国际化人才的一大优势。中外合作办学项 目本科教育阶段一般采取以下几种模式: 一是 “ $2+2$ ” 分段培养模式, 即学生通过高考录取后, 一、二年级 在国内院校学习, 后两年可自主选择在国内院校或国 外合作院校进行学习, 所学专业相似或不变。二是 “3+1”分段培养模式, 即学生通过高考录取后, 一、 二、三年级在国内院校学习, 后一年可自主选择在国 内院校或国外合作院校进行学习, 所学专业相似或不 变。三是 “ $4+0$ ”培养模式, 即考生通过录取后, 学生 四年都是在国内上课, 但采用国外的教学大纲和考试 方式, 引进国外的原版教材及教授, 整体教学模式与 国外合作院校保持一致。

以笔者所在的“广商-BU”双学位项目为例, 该项目 采取 $2+2$ 联合培养模式, 充分发挥中外高校的教学优 势, 学生第一、二年在广州商学院学习, 第三、四年 赴合作院校美国贝佛大学学习。在广州商学院的教学 以基础教育为主, 主修包括思修、近代史、毛概、体 育、形式与政策等公共必修课程及英语国家社会与文 化、学术写作等专业基础课程, 配备具有海外留学背 景的师资和高水平雅思教学团队授课, 采取双语教学 和英文原版教材。在美国贝佛大学的教学则以专业核 心课程为主, 配备高水平的国外专业教授团队, 采用 全英小班授课, 课程教学方式也比较灵活多样, 融合 项目教学法、讨论法、 P B L (以问题为中心的教学 法) 、练习法(习题或操作)、案例教学法、讲授法等 多种授课方式，从而最大化支持教学目标达成。

显而易见，中外合作办学项目中前2-3年国内基础 教育课程担任着课程思政“主战场”的重担，而后1-2 年的专业核心课程多数于国外合作项目院校进行教 学, 较多受到国外合作院校的各类框架的制约, 如教
学时间、教学地点、教师主体、教育理念、教学模式 等均与国内教学存在较大差异, 课程思政的实施势必 难展身手。此外, 外方院校一般“对强制性修读思政 类课程积极性不高, 在与外方谈判和具体教学过程中, 中方在课程设置中要体现实打实的思政课有一定的 难度”[19]。因此, 作为跨境办学的中外合作办学高校, 如何加强学生基础学习阶段的思想政治教育, 如何在 专业课程阶段有效融入思想政治教育元素, 确保基础 学习阶段与专业学习阶段思想政治教育的一致性与 连贯性, 进而构建国内国外“双校区”协同模式课程思 政大格局, 是保证该类项目的社会主义办学方向和落 实立德树人的根本任务和重要途径, 也是该类项目亟 待解决的第三个重要问题。

\section{4. 高校中外合作办学项目课程思政建设的出 路}

中外合作办学项目课程思政建设取得的成绩与已 有的研究可为其深入发展提供实践参考与理论支撑, 凸显的一系列亟待解决的问题也彰显未来发展的工 作导向。当前中外合作办学高校课程思政所面临的中 外师资配置、中外教材建设、中外校区协同育人等困 境如同一把“双刃剑”，一方面阻碍了课程思政改革创 新的具体实施和推进力度，制约课程思政效果的发挥。 另一方面, 坚持立德树人为目标, 以问题为导向, 突 破课程思政建设过程中存在的重点难点问题, 将能科 学合理拓展中外合作办学项目专业体系设置的广度 和深度。面对困境, 积极应对是良策, 需要从以下三 个方面积极构建中外合作办学多元化背景下具有鲜 明特色的思想政治教育工作新模式。

\section{1. 聚焦立德树人的总目标, 注重集合课程思 政的向心力}

高校中外合作办学项目旨在培养热爱祖国, 具有 民族情怀和国际化视野, 具备讲好中国故事, 传播中 华文明能力的高素质复合型人才, 要全面贯彻党的教 育方针落, 紧紧围绕立德树人的根本任务, 大力营造 课程门门有思政, 教师人人讲育人的建设氛围, 集合 课程思政的向心力。教师是推行课程思政的执行者, 是种好课程思政责任田的主力军, 其思想政治素养和 教育教学能力的高低直接决定课程思政建设的效果。 全面推进课程思政建设, 教师是关键。高校中外合作 办学项目的师资队伍包括中方教师和外籍教师, 要实 现三全育人的格局, 必须建设好整个教师队伍, 提升 教师的政治素养, 调动所有教师的参与性、积极性与 创新性。

\subsection{1. 积极探索思政课教师与其他各类课程教 师协同育人的新机制}

思想政治教育不单只是思政课教师的职责，其他 类课程教师同样承担着教书育人的重担。搭建教师合 力平台, 可以通过马克思主义学院思政课程骨干教师 与专业课程教师协作共同担当育人之责, 从教学大纲、 
教学标准、教案入手, 思政课程老师帮、扶、带专业 任课老师，精心挖掘课程文本、教学内容、教学案例 等方面的思政元素。“思政课程到课程思政绝不是简 单的文字次序调换”，教师 “必须应用思想政治理论 教育的学科思维处理教材、组织教学内容, 充分挖掘 蕴含在相关知识中的教育因素, 时时扣住德艺双馨的 “命脉” , 助力学生的全面发展” ${ }^{[20]}$ 。高校教师要深 刻认识课程思政与思政课程的有机统一关系, 二者都 是要解决高等教育 “培养什么样的人、如何培养人、 为谁培养人” 的根本问题, 虽有一定的差异, 却相辅 相成并相得益彰。

\subsection{2. 积极构建中国教师与外籍教师协同育人 的新模式}

课程思政是具有中国社会主义特色的一种教育思 维理念。由于中西文化的差异与思维模式的不同, 部 分外籍教师对课程思政育人认识不足, 认为课程思政 是中国教师的事情而不愿参与。要及时扭转此部分外 籍教师的认知误区, 可以通过开展集中培训交流、课 堂教学观摩、建设经典案列库, 宣传课程思政外籍教 师先进典型等方式, 不断融合中国教师与外籍教师队 伍教育教学理念, 充分发挥中国教师课程思政育人的 积极性、主动性与创造性, 提升外籍教师对课程思政 建设的认同感、获得感与参与感, 共同为培养社会主 义建设者和接班人的宏伟大业添砖加瓦。

\section{2. 把握教学育才的规律性, 注重提升课程思 政的牵引力}

教育有其自身的特点与规律, 做好高校中外办学 项目课程思政育人工作, 要遵循学科建制规律, 遵循 课程体系规律, 遵循学生成长规律, 遵循知识本身的 内在规律, 才能有的放矢, 不断提高工作能力和水平。

\subsection{1. 遵循学科特点与课程体系规律, 科学合理 地推进课程思政}

2020年教育部明确指出要有针对性地结合各类课 程特点和专业特点推进课程思政教学实践 ${ }^{[21]}$ 。只有厘 清各类课程和各类专业自身特点和内在规律, 才能在 课程教学实践中有机融入相应的课程思政育人元素, 有效推进课程思政建设。例如, 文史哲学科往往强调 马克思主义世界观和方法论，历史与现实、理论与实 践等的辩证思维; 经管法专业注重经济体系、国家战 略、法律法规等的理解把握; 公共基础课多涉及培养 学生的道德修养、人文素质、科学精神、国家安全意 识等, 注重在潜移默化中坚定学生理想信念; 而实践 类课程更注重学思结合、知行统一, 培养创新精神、 创造意识和创业能力。

\subsection{2. 遵循学生时代特点与个体成长规律, 偱 序渐进地实施课程思政}

一方面, 每个时代都有其特殊的年代印记, 出生 于此年代的群体与来自于其他年代的群体往往在生 活体验与价值取向上呈现出明显的差异。例如目前各
高校在校学生整体上出生于2000年前后, 是典型的 “ Z 世代”，其成长伴随着网络短讯、智能手机、平板电 脑等科技产物, Z世代的整体性特征表现为从小就浸 润在数字化虚拟网络空间, 追求新技术, 乐于在线互 动, 但对深度内容缺少接受度, 抗拒统一的、逻辑规 整的表达, 是数字原生代, 是互联网和新媒体的“原 住民”[22]。面对Z时代的学生特点, 课程思政的育人 要在学生喜闻乐见的社交媒体学习模式中进行, 通过 虚实相生的智慧教学环境, 融入学生的“生活圈”, 才 能对其进行知识的传授与价值的引领。另一方面, 要 根据学生在不同学习阶段的身心发展特点, 有针对性 地开展教育引导。比如对于大一新生, 要以目标为导 向, 引领学生积极树立人生目标, 养成良好的学习和 生活习惯; 对于大二的学生, 要以能力为重点, 鼓励 学生在课程学习、课外实践、团学活动中不断提升自 我; 而对于大三以上即将毕业的学生, 要以责任为主 线, 引导学生正确处理个人理想、集体利益与国家荣 誉之间的关系，在毕业、择业、就业中进行正确的选 择, 在学校、家庭、社会中形成正确的价值判断。

\subsection{3. 遵循知识本身内在规律, 有针对性地践 行课程思政}

科学知识内在的联系在教材的编写上体现最为明 显。教材目标的预设、教材内容的选择、教材架构的 重组均是编者精心筹划的结果，体现了编者的世界观 与方法论。教师和学生在使用某一本教材时, 总是在 不知不觉中受到编者的世界观与方法论的浸润。因此, 在国内教材的选择上, 要坚持目标性原则、准确性原 则、科学性原则和实用性原则, 具体指选择知识与技 能目标明确、能力培养清晰与价值引领明显的教材; 选择知识构架准确、过程与方法清晰、文字表述简洁 的教材; 选择目录章节编排合理、内容结构复合逻辑、 知识结构循序渐进的教材; 选择符合学校人才培养目 标、符合学生水平能力、切合学生兴趣点的教材。国 外教材则由国外具有多年行业经验的专家或教师编 写, 由国外出版社校审出版, 能原汁原味体现编者的 语言风貌、逻辑思维、价值理念等, 在进行选择和征 订时, 除了遵循以上原则, 还需要任课教师、教学监 督部门等对其内容进行多次审核, 确保原版教材的观 点立场、学术价值、难易程度等均符合国内学生的实 际水平。在有条件的高校, 还可以搭建项目平台, 鼓 励教研能力强的教师结合原版教材、国内教材与学生 实际学情, 编写符合中外合作办学项目学生需求的本 土化、独特性的校本教材, 充分挖掘各类教材的思政 教育元素，提高人才培养质量。

\section{3. 拓宽实践铸魂的主平台, 注重加强课程思 政的接续力}

高校中外合作办学项目课程思政育人的落地实施, 需要搭建各类教学实践平台和学术研究平台, 以项目 为引领, 组织师生在教学实践中探索模式与验证效果, 
在理论研究中领会内涵和拓宽思路, 实现全员全过程 全方位育人铸魂，夯实课程思政建设的接续力。

\subsection{1. 探索国内、国外“双校园”协同育人的 新范式}

国外与国内 “双校园”协同模式是当前国内高等 教育对外交流和合作的一种重要形式。此模式对学生 有较大的吸引力, 学生不仅能接受到完整的知识教学, 还能得到不同文化背景的生活体验 ${ }^{[23]}$, 充分利用国内 国外不同高校的优质教学资源, 最大化地满足学生多 元化的学习需求, 拓展学生的学习视野。国内校区基 础学习阶段的各类通识课程, 如思修、近代史、毛概 等能有效确保课程思政育人的实施，而国外校区的专 业课程往往因教学时间、教学地点、教师主体、教育 理念、教学模式等差异而受到国外合作院校的约束, 课程思政容易出现断层和脱节。中外合作办学项目学 子踏出国门学习深造, 如何才能不忘初心、胸怀祖国? 国外校区的中国学子可以积极参加国外的志愿者活 动、公益活动、各类文化节等, 既能锻炼自己所学知 识技能, 又能展示良好的个人品质风貌, 弘扬中国优 秀文化传统。同时, 还可以实行 “国外学子国内导师 制” , 组织国内思想素质过硬的教师, 通过远程通讯 方式, 对国外校区中国学子的学习、生活、心理状态 等进行跟进和疏导，确保课程思政育人持续不断层。

\subsection{2. 优化第一、第二课堂统合育人的大格局}

高校的人才培养系统中一般包括注重理论知识传 授的第一课堂和注重实践创新能力培养的第二课堂。 在三全育人课程思政的大背景下, 第一课堂很好的发 挥了价值引领的育人功能, 第二课堂同样功不可没。 第二课堂作为“三全育人”视阈下高校十大育人体系 实践探索的主阵地, 已经从传统的课外活动向综合素 质提升的新时代高等教育要求转变 ${ }^{[24]}$ 。高校中外合作 办学项目旨在培养具有家国情怀、国际化视野的复合 型应用型人才, 要在第一课堂理论学习的基础上, 更 加重视发挥第二课堂的育人功能, 以丰富的校园文化 生活为载体, 引导学生积极参与第二课堂, 在团学竞 赛、志愿服务、勤工俭学、实践实训中锻炼成长、修 炼品格、塑造价值。例如, 在“讲好中国故事, 传播 好中国声音”微团课大赛中读党史、学典型、讲文化, 学会用中国的眼光看世界; 在“模拟联合国”活动辩论 赛中, 探讨国际合作、消除贫穷、环境保护等全球性 问题, 学会用世界的眼光看世界, 具有更广阔的学术 视野。

\subsection{3. 打造科研团队、思政课题齐头并进的新 局面}

以问题为导向, 以项目为平台, 组建包括中方教 师与外籍教师、思政课程教师与专业课程教师的复合 型课题团队, 研究当前思政热点, 加强课程思政建设 中重点、难点、前瞻性问题研究, 积极推动课程思政 教育教学改革。其次, 鼓励课题团队申报试点项目、 试点课程和试点课堂, 通过试点先行、精准培育、逐 步推广, 分阶段推进课程思政。再次, 聚合高校育人
资源, 建设课程思政教学改革优秀案例库, 围绕课程 教学中的某一章节 (模块), 深入发掘各学科、专业、 课程中蕴含的思想政治教育元素, 明确课程思政育人 教学目标, 优化课程思政育人教学设计, 突出思政元 素育人的融入点, 在教学理念、教学思路、内容形式、 方法手段等方面积极创新, 可以起到示范引领、榜样 带动的作用。最终, 教师在项目研究中深化对课程思 政内涵的理解, 拓宽课程思政建设的实现路径, 不断 开创课程思政建设的新模式。

\section{5. 结论}

课程思政是当前高校学生思想政治教育的新模式, 需要用习近平新时代中国特色社会主义思想指导实 践。作为我国教育对外交流与对外合作的重要载体, 高校中外合作办学项目由于其办学过程中有国外师 资、国外教材、国外教学模式等国外教育元素的参与, 课程思政的推进更具有特殊性、复杂性与紧迫性, 课 程思政建设与实践也面临其特有的困境。以问题为导 向, 关注并解决课程思政推进过程中面临的重点、难 点及普遍性问题, 能揭示高校中外合作办学教育特有 的思想政治工作规律、教书育人规律和学生成长规律, 能科学合理拓展中外合作办学项目专业体系设置的 广度和深度, 助力培养中外合作办学项目学生成为符 合中国特色社会主义建设事业和地方经济发展需要 的高素质国际化应用型人才。

\section{致谢}

本文系广东省高校思想政治教育课题“中外合作 办学背景下应用型本科高校课程思政建设困境与对 策研究”（2020GXSZ099）、广州商学院2020年高等 教育教学研究和改革项目 “应用型本科高校中外合作 办学项目课程思政教学实践探索”、广州商学院课程 思政 “四个一”试点课程《英语阅读》

（KCSZSDXM202082）的阶段性研究成果。

\section{REFERENCES}

[1] Yufeng Wan. How to integrate the salt of Ideological and political education into the curriculum feast $[\mathrm{N}]$. China Education Daily, 2020-06-10.

[2] Xuan Qiu. Exploration of international talent training mode -- Establishment and implementation of international curriculum system of Sino Canadian cooperative education project of Ningbo University [J]. Journal of Ningbo University (EDUCATION SCIENCE EDITION), 2002, 24 (5): 74-76, 99.

[3] Zhixiang Zhuang, Tianlin Han, et al. On the construction of teaching material system for the cultivation of international innovative foreign language talents [J]. Foreign language circles, 2013, (05): 45-50. 
[4] Hui Yin, Xiaoxue Li. On the construction of quality evaluation index system for application-oriented Sino foreign cooperative education [J]. Journal of Anhui Radio and Television University, 2018, (04): 61-68.

[5] Xin Li, Yu Chen. Research on the construction of academic evaluation system of Ideological and political courses in Sino foreign cooperative education projects $[\mathrm{J}]$. Science and education guide, 2020, (33): 89-90.

[6] Jia Zeng. Three dimensions of constructing the curriculum system of Sino foreign cooperative education project in applied local universities [J]. Teaching research, 2020,43 (05): 41-45.

[7] Changgui Shi, Shengzhi Wu. On the party construction of students under the mode of Sino foreign cooperation in running schools [J]. Journal of Shanxi University of Finance and economics, 2012, 34 (S4): 100.

[8] Yuefei Feng, Ping Liu. Investigation and Research on Ideological and Political Courses under the mode of cooperative education in China [J]. Journal of higher education, 2016 (4): 38-39, 41.

[9] Xinqiang Wei. Problems and countermeasures in the construction of teachers for Sino foreign cooperative education in Colleges and Universities: a case study of Henan Province [J]. Henan Social Sciences, 2012, (09): 64-65.

[10] Ke Sun. Research on the construction of Ideological and political teaching staff in Sino foreign cooperative education [J]. Journal of Zhejiang Wanli University, 2018,31 (02): 97-101.

[11] Zhijun Qing. Reflections on the internationalization of teaching staff in Sino foreign cooperation in running schools: a case study of Hainan Normal University [J]. Western academic journal, 2020, (13): 98-100.

[12] JinFang Li. Exploration on bilingual teaching practice of economics and management majors in normal universities under Sino foreign cooperation [J]. Journal of Hubei open vocational college, 2020,33 (16): 130-131, 134

[13] Wei Chen, Jiasi Hou, et al. Creating a mode of Ideological and political education combined with innovative and practical education -- Exploration and practice of Ideological and political education in engineering Sino foreign cooperative schools [J]. Journal of Sichuan University for nationalities, 2020,29 (02): 55-59.

[14] Ye Xu. Research on the optimization of English Teaching in Sino foreign cooperative education projects under the concept of "curriculum, ideology and politics” [J]. Zhili, 2020 (14): 176-177.

[15] Shuyao Xu. The implementation of curriculum ideology and politics in the teaching of Comprehensive English in Sino foreign cooperative education [J]. Journal of Jilin Normal University of engineering and technology, 2020,36 (04): 54-56.

[16] Jwz [2006] No.5, Ministry of education of the people's Republic of China, Opinions of the Ministry of education on some issues concerning Sino foreign cooperation in running schools, 2006-02-07.

[17] Peng Yi, Dingfang Shi. Difficulties, characteristics and practical exploration of Ideological and Political Education Reform [J]. Journal of Chongqing University of Arts and Sciences (SOCIAL SCIENCE EDITION), 2020 (4): 124-132.

[18] Ministry of education of the People's Republic of China (85) Jiao Li Cai Zi No.001 “Notice on some problems of textbook work in Colleges and universities”, 1985-01-09.

[19] Xiaojie Wu, Ziyi Jia. Thoughts on the construction of Ideological and political course in Sino foreign cooperative education -- Taking Shanghai Jiaotong University as an example [J]. Journal of higher education, 2018, (19): 191-193.

[20] Kaijin Qiu. How to go from ideological and political curriculum to ideological and Political Curriculum [N]. China Education Daily, March 2, 2017.

[21] JG [2020] No.3 Document of the Ministry of education of the CPC Central Committee,Guiding outline for ideological and political construction of higher education curriculum, 2020-06-01.

[22] Xitao Zhang, Xin He. "Breaking the circle” and "Integration": Analysis on the mixed teaching path of "generation Z" college students [J]. Public relations world, 2020, (22): 166-167.

[23] Zhengquan Chen. Research on the construction of "double campus" talent training mode of Sino foreign cooperative education [J]. Journal of Chuxiong Normal University. 2011, (05): 89-92.

[24] Guoqiao Zhou. Innovative exploration of second classroom education in Colleges and universities from the perspective of "Three complete education" [J]. School party construction and ideological education. 2020, (10): 52-54. 